\title{
Analysis on the State of Arts and Education Curriculum for Fire Safety Policy in Korea
}

\author{
Young-Jin Kwon \\ Fire and Disaster Prevention, Hoseo University, Korea
}

Thank you very much for your kind introduction. My name is Kwon, I am from Hoseo University from South Korea. I would like to update you about the current situation with South Korea with fire safety and education curriculum. (Figure 3-6-1) First of all thank you very much for your invitation to the TUS Forum and although that I would like to my capability is rather limited, but I would like to make further contribution to these activities. This is the menu of my presentation.

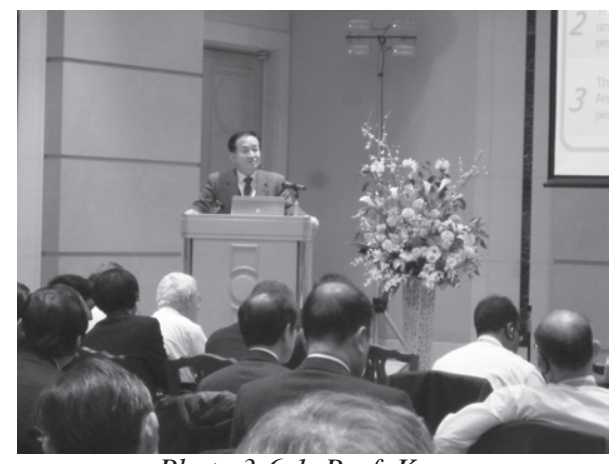

Photo 3-6-1 Prof. Kwon

First is the introduction and also the big issues for fire prevention in Korea. (Figure 3-6-2) For these big issues how we are trying to deal with these big issues. I would like to share our experiences of the counter measures and also at the university what we are doing in academic activities, mostly for our classes and also the conclusion and future tasks.

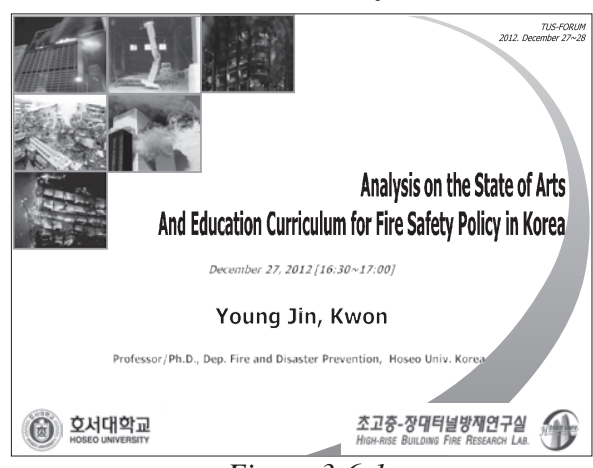

Figure 3-6-1

\begin{tabular}{|l|}
\hline Contents \\
\hline (1) Introduction \\
(2) Big Issues for Fire Prevention in Korea \\
(2.1) Trends and Fire Case Analysis \\
(2.2) Changes of Fire Prevention Countermeasures \\
(3) Hoseo Univ. Activities for Fire Prevention Design \\
(4) Condusion and Future Tasks \\
\hline
\end{tabular}

Figure 3-6-2

For the big issues actually we are having an increasing number of high rises. (Figure 3-6-3) This is the situation in 1950s, there were many developments in South Korea. But since around 1970s particularly that the weight reduction of the structures was the main focus, so there is an increasing number of high rises.

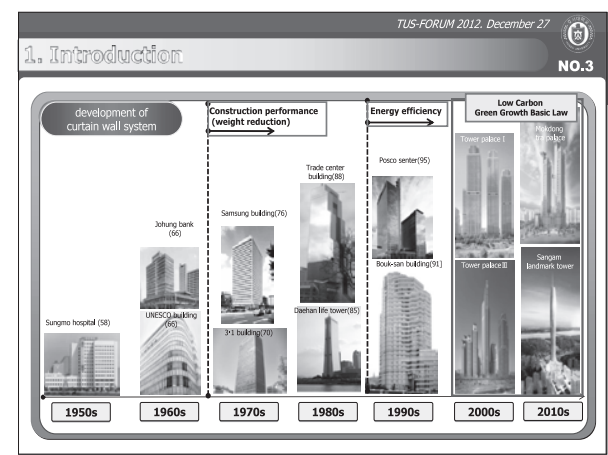

Figure 3-6-3 
Most recently there is a focus on energy efficiency of those high rise buildings. Unlike Japan, in South Korea, for the private homes energy efficiency is high and also the office buildings are having more and more energy efficient systems. (Figure 3-6-4) These are the focus areas for energy efficiency. Since 1985, this graph shows the number of the height of the high rises that you can see in relatively short period. There is a very high number of high rises built.

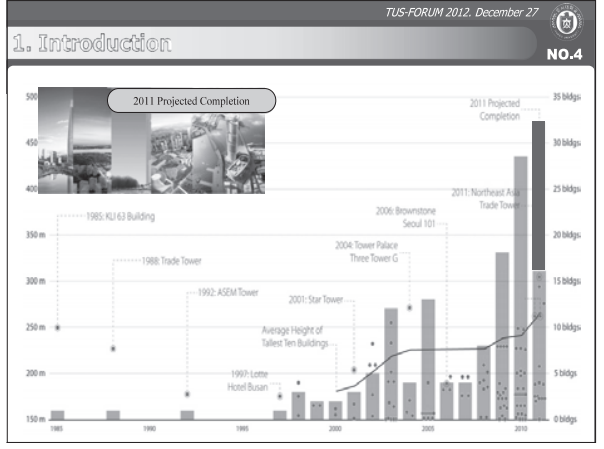

Figure 3-6-4

I recognize that the time is limited, so I would like to just feature some high rises. (Figure 3-6-5) Right now, it's being constructed, this is the second Lotte World building of which construction is now underway and also in Busan City has the more and more high rises.

This building is Lotte Town of Busan and number of stories is 107 and still it's under construction. (Figure 3-6-6)

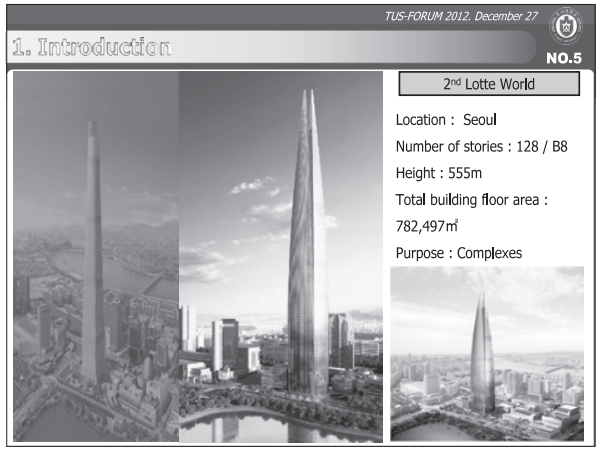

Figure 3-6-5

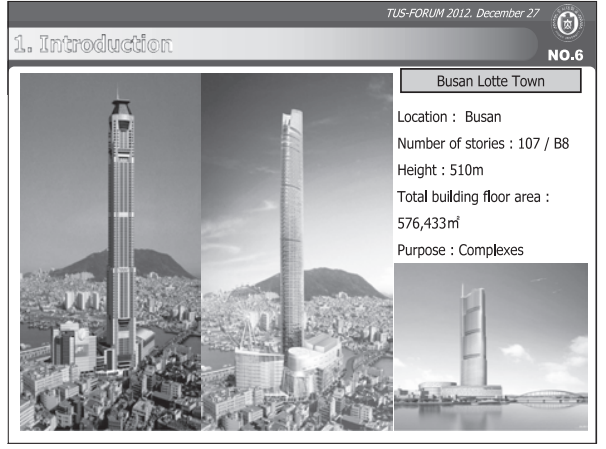

Figure 3-6-6

This is the Incheon area, 151, 151 Tower is the buildings name. It's still at planning stage. (Figure 3-6-7)

This is the Seoul LITE Tower and 656 meters high and the number of stories is 133 stories. This is still in the planning stage. (Figure 3-6-8)

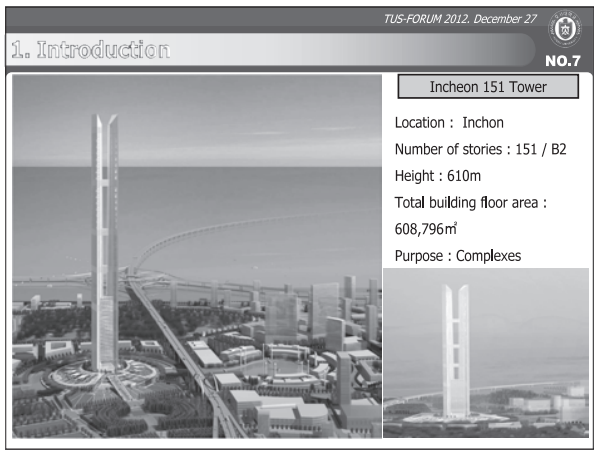

Figure 3-6-7

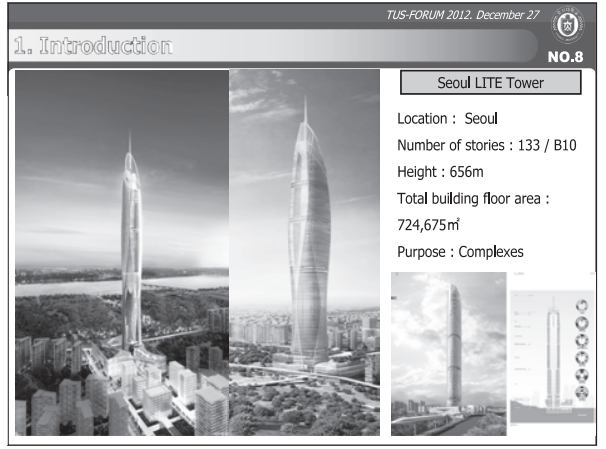

Figure 3-6-8 
This is very unique project. As you can see in the one district of the city there are so many high rises, this project is titled as Yongsan Dream Hub. (Figure 3-6-9) There would be a concentration of high rises. This is still at the planning stage.

This is the Hyundai company's buildings which is now being planned. (Figure 3-6-10)

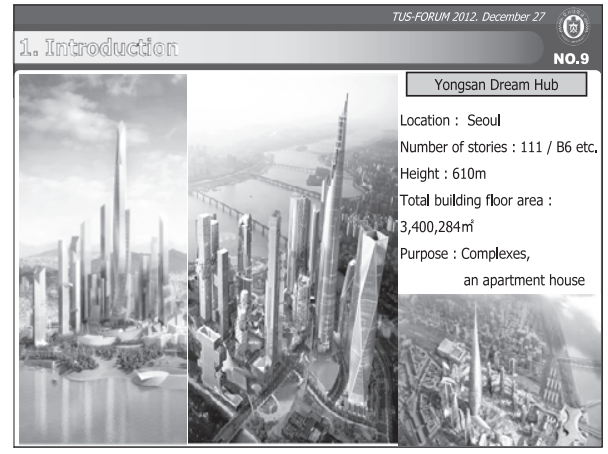

Figure 3-6-9

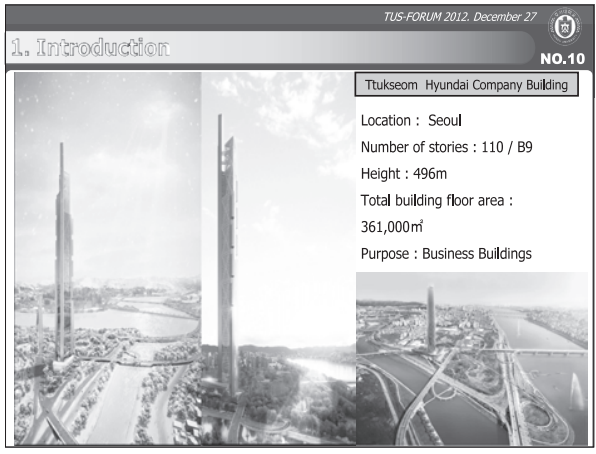

Figure 3-6-10

This is another project in Busan, the Haeundae Wa project in Busan that's in planning stage. (Figure 3-6-11)

Busan and in Incheon as you can see there are some projects to build and plan high rise buildings. (Figure 3-6-12)

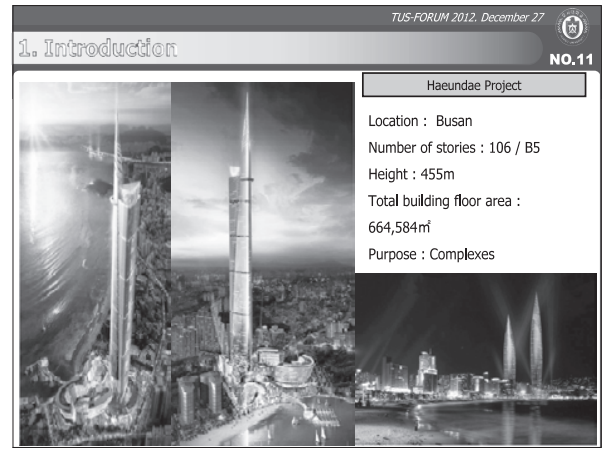

Figure 3-6-11

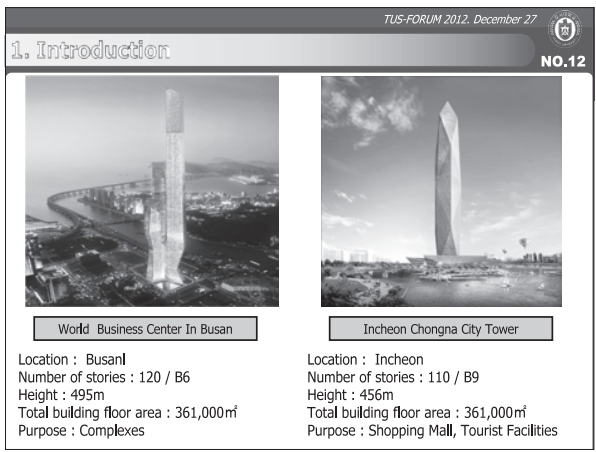

Figure 3-6-12

This is photos of the fires of the high rises globally and also we have had some terrorism incident. (Figure 3-6-13) In South Korea we are so nervous about the danger of the terrorism particularly we are so close to the North Korea and this terrorism-related fire incident is also one potential big issue.

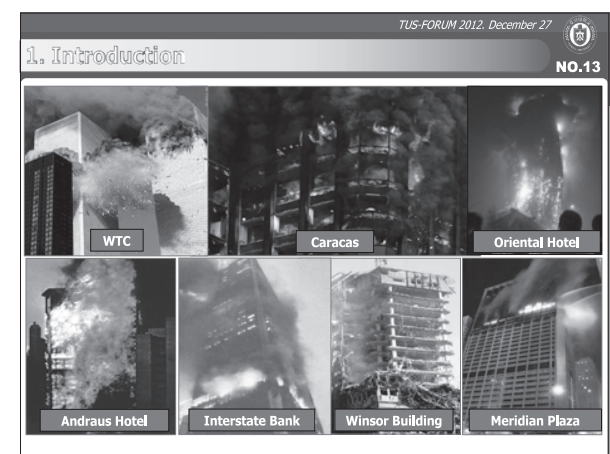

Figure 3-6-13 
The second big issue is the development of underground space. So in comparison to the high rise building projects there is also more projects of the underground huge space development project. (Figure 3-6-14) There is underground parking spaces and inside the parking spaces there could be gasoline or the hybrid fuel cars as well as electrical wires and some of them are multiplex and multipurpose facilities. For first time visitors they have no clues to which entrance or the exit they

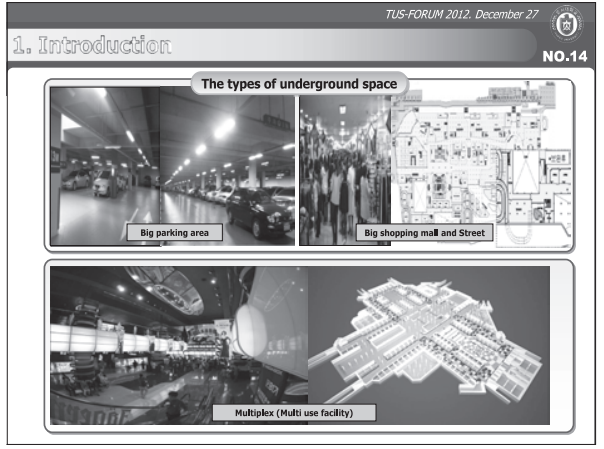

Figure 3-6-14 can use. This is very huge underground space to be developed. In terms of fire safety consideration this is posing a significant challenge, but the designers and the builders because of their economic situation this is one of the most talked about topics nowadays.

Also U-Smart Highway project is another project being talked about. (Figure 3-6-15) This is about the subways and there are many commuters who would be taking more than 1 hour subway ride to commute to the city center offices. This U-Smartway or U-Smart Highway is built and in-depth the tunnel and railways, so it takes just 30 minutes from Seoul City Center to the Gyeonggi Province. So this is still at planning stage. This is also the project linking Korea and China and

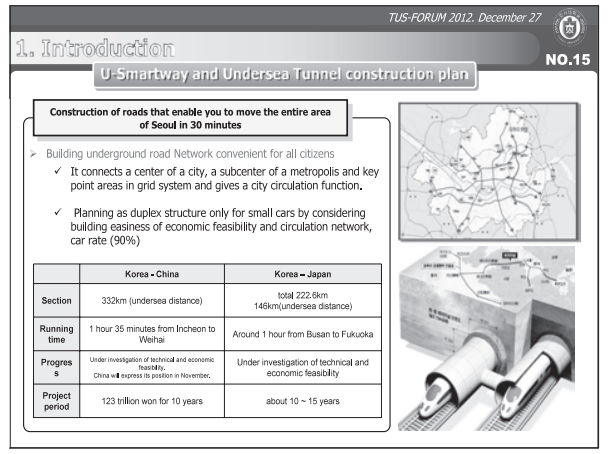

Figure 3-6-15 also the project of undersea tunnel linking Korea and Japan. This is examples of the big issues.

However, as you can see long underground tunnel there are an increasing number of tunnel fires too and further point (Figure 3-6-16)

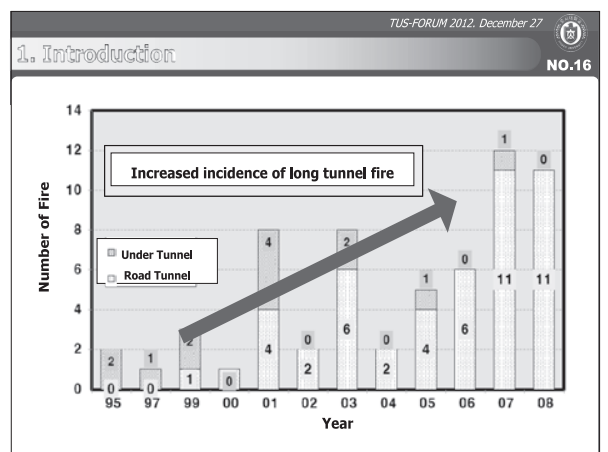

Figure 3-6-16 
I would like to talk about is that in South Korea there are many barracks or the shanty towns and also the outdoor markets and we have lots of concentrated places having so many wooden houses. (Figure 3-6-17) If there is arson or fire accident in these areas the damage would be significant. Prevention of the fire in these districts is one of the great challenge for us.

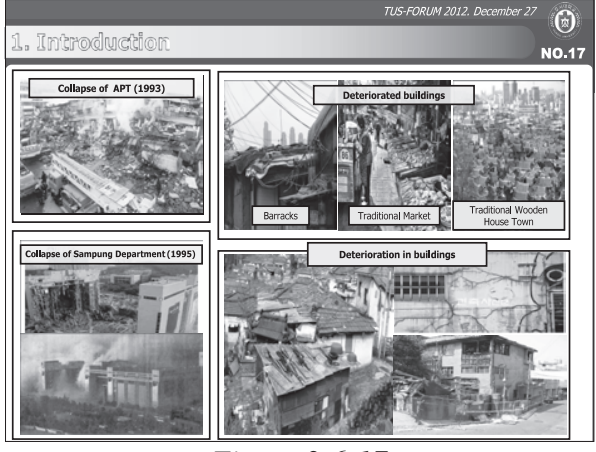

Figure 3-6-17

In Japan there was some Japanese presenter to talk about the acceleration of aging societies and population. (Figure 3-6-18) This is another big issue in Korea. By 2020, exceeding the speed of the aging population in Japan, the Korea would be entering into the aging society at higher speed, so this is one of the big challenges too. Also the number of the people with disabilities, now standing at 5\% nowadays would be also posing a challenge for the fire safety areas. Having said that as you can see here there is the high

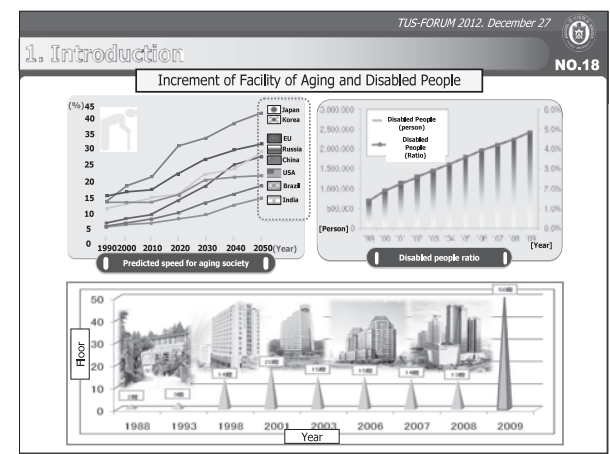

Figure 3-6-18 rises for the elderly citizens where while we are having aging population in a society too.

This graph chart shows that the situation in South Korea since around 1990s according to this statistics number of fire is up and China it's down and Japan is rather stable and some said that this - he cannot believe in this statistics, but this is the statistics or data I got to share. (Figure 3-6-19) But this, the 10\% is arson; 10\% of the fire is caused by arson, so this is the fifth big issue for us. I covered these five big issues and what we are doing against them as countermeasures and at our university what kind of training courses, educational courses we're doing. (Figure 3-6-20)

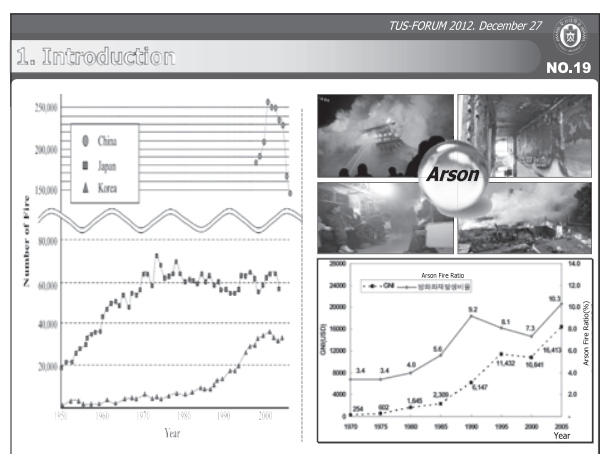

Figure 3-6-19

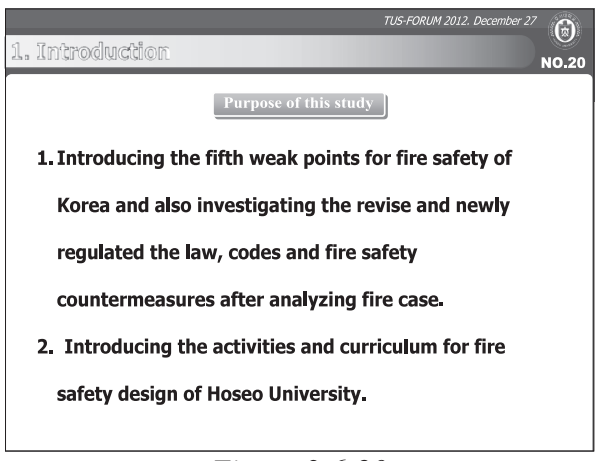

Figure 3-6-20 
First I would like to share on these fire cases for these five points. (Figure 3-6-21) The first point I would like to call for your attention in the fire, in 1971; then the highest hotel was on fire and the December day, and 1971 was the date of the fire for that building. I would like to show you the videotape of that fire incident back then.

[Video]

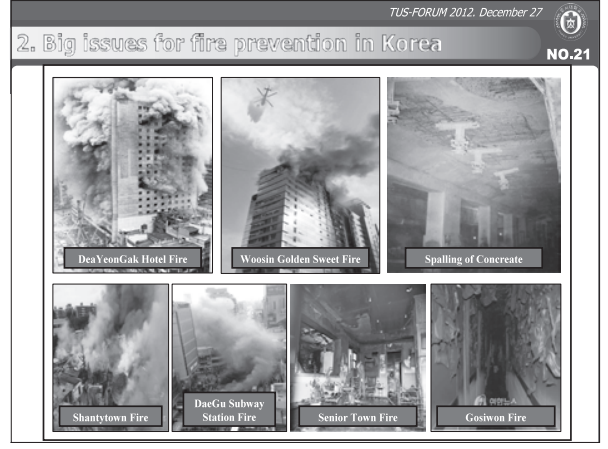

Figure 3-6-21

The fire took place on the Christmas Day on the 2nd floor, so within 20 minutes or so it went up to the 22 nd floor from the 2 nd floor. (Figure 3-6-22)

[Video]

Thirty-eight people died. Some of them jumped from the floor. (Figure 3-6-23)

[Video]

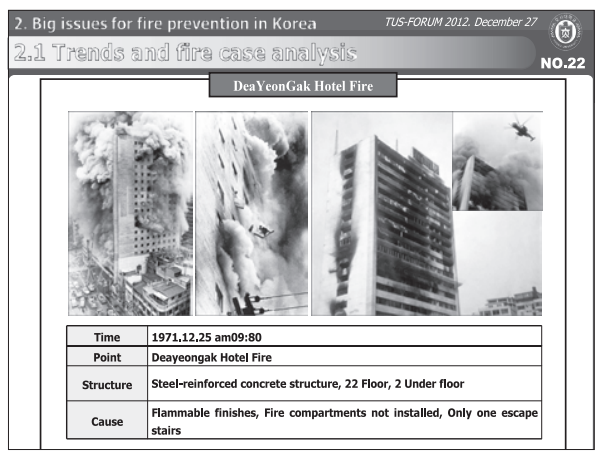

Figure 3-6-22

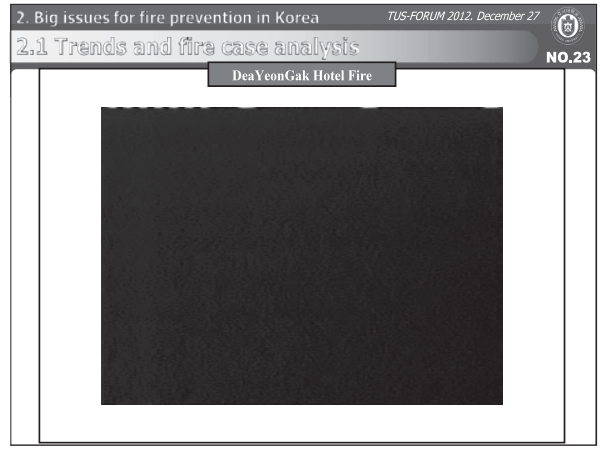

Figure 3-6-23

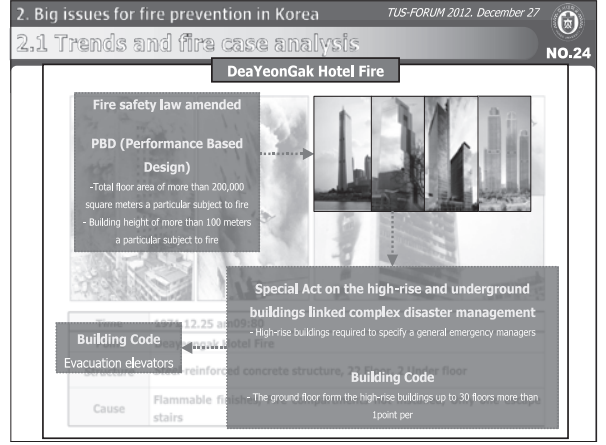

Figure 3-6-24 underground buildings like the complex disaster management purposes. 
Next example is in the Busan City and it is another high-rise building and it's because of some structures and Professor Ohmiya and also the Professor Hayashi (BRI) of the research institute visited the site of the fire. (Figure 3-6-25) I was also involved as an assistant and I would like to show you the video.

This video was shot by a fire fighter. (Figure 3-6-26) From the 4th floor, fire started and through the ground and there was a tunnel effect, so quickly it spread up to the 38 th floor and luckily only three sort of were affected. There was no death.

Having said that in this kind of the reinforced buildings that right now, the government, they encouraged and actually required that noninflammable material should be utilized and also there was there some materials and also back in 2004 there was another incident that we

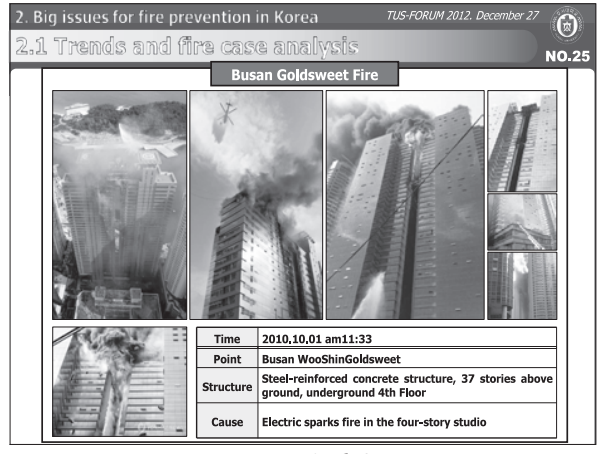

Figure 3-6-25

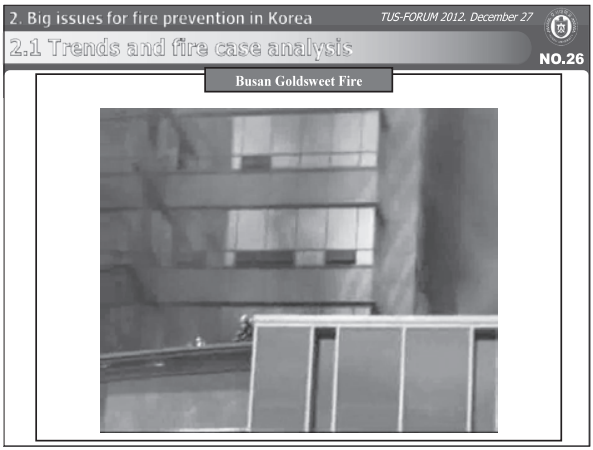

Figure 3-6-26 found that some structure was very weak in fire in 2005. (Figure 3-6-27, 2-6-28, 3-6-29)

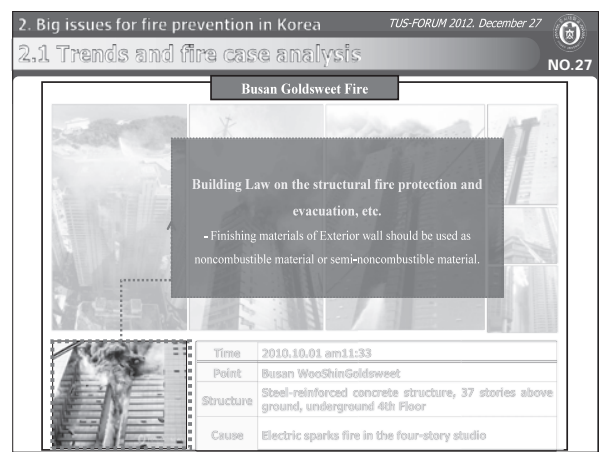

Figure 3-6-27

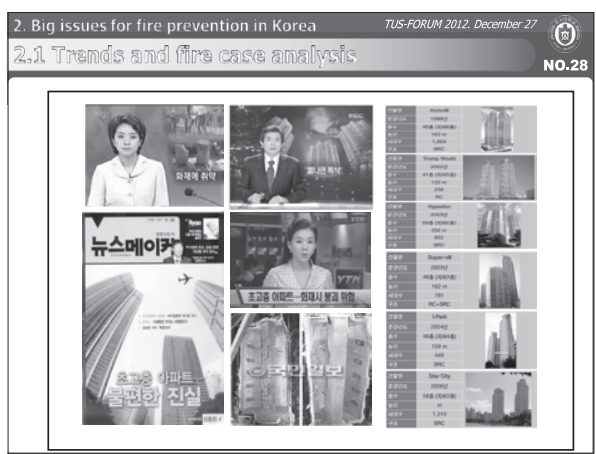

Figure 3-6-28

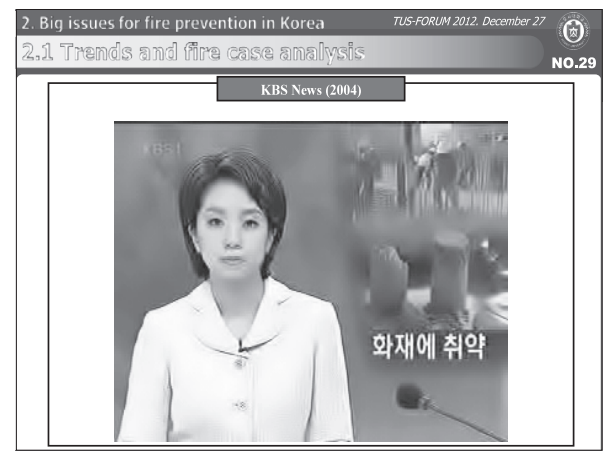

Figure 3-6-29 
This is Madrid, the Spain example. (Figure 3-6-30) Because of several reasons there was this partial collapse of the building and if the level is exceeding 50 mega pascal in South Korea as you can see from this video. (Figure 3-6-31)

[Video]

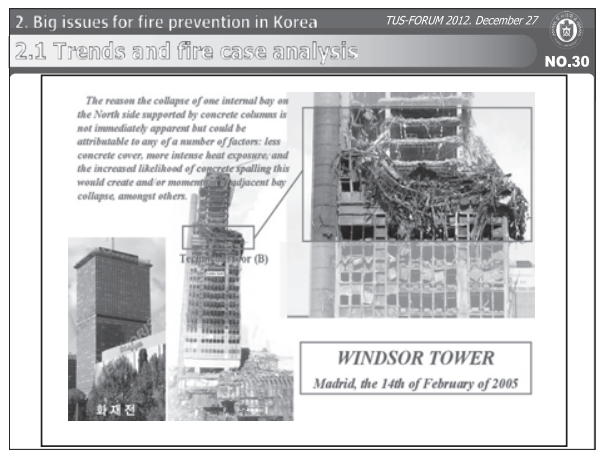

Figure 3-6-30

We needed to protect people, however, the building would be collapsed and destroyed by the fire. This is very serious issue. In South Korea there is association with architects and the association published that management standards on the fire resistance performance of the column beam for a high strength concrete, we carried out the casting system so that they needed to pass the test to utilize the materials. (Figure 3-6-32)

This is Daegu Subway fire. (Figure 3-6-33) It happened in the year 2003. Approximately there were 300 casualties due to the fire.

In South Korea since 2003 and 2004, there were some rules and regulations in particularly for the 2007 there were some tunnel fires and if the level exceeds the $90 \%$ then there should be a mandated fire inspection system and that's a part of the rule. (Figure 3-6-34)

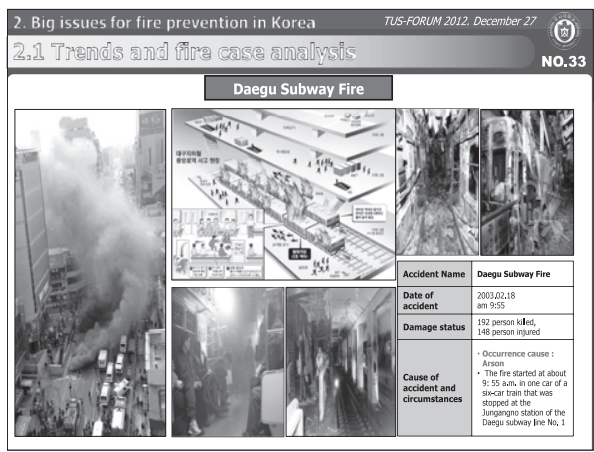

Figure 3-6-33

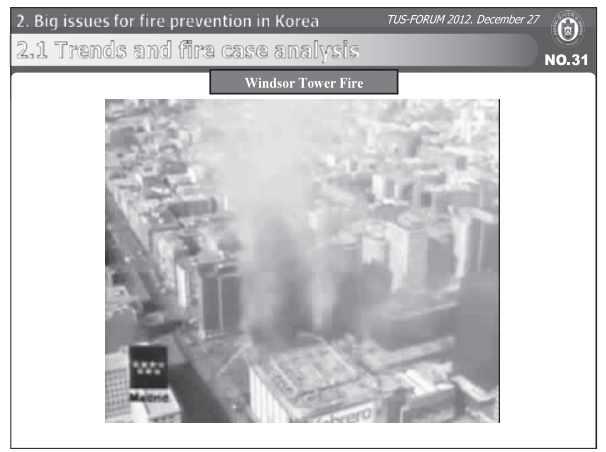

Figure 3-6-31

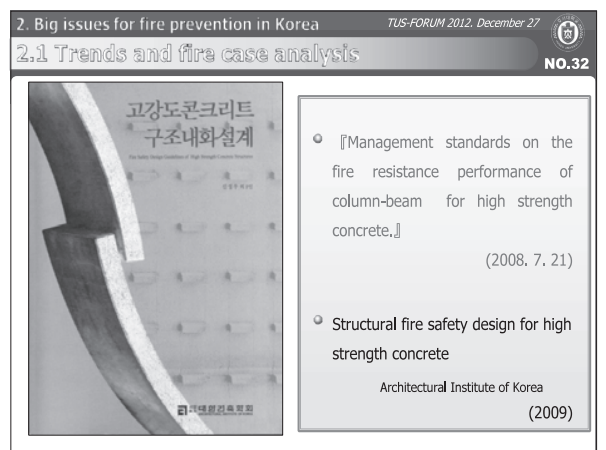

Figure 3-6-32

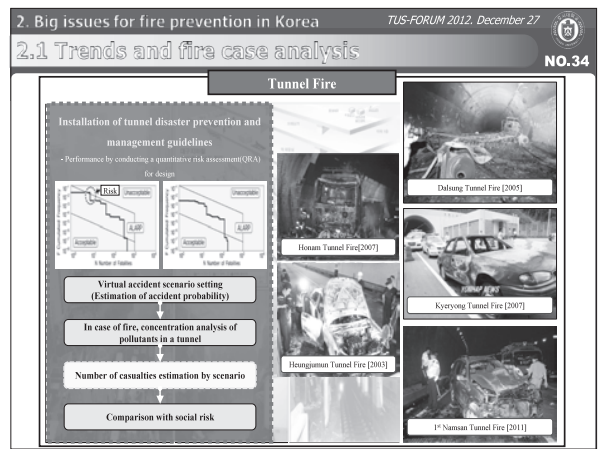

Figure 3-6-34 
Not just the Seoul but also these mountainous areas, there used to be a tunnel in the mountain regions, but even within the Seoul there is a lot of tunnels and also the underground spaces. (Figure 3-6-35)

As in Japan the situation is the same. (Figure 3-6-36) There are many tunnels and underground spaces. Professor Kan (Central Police Univ.) mentioned that the safety system in South Korea, Professor Kan, myself

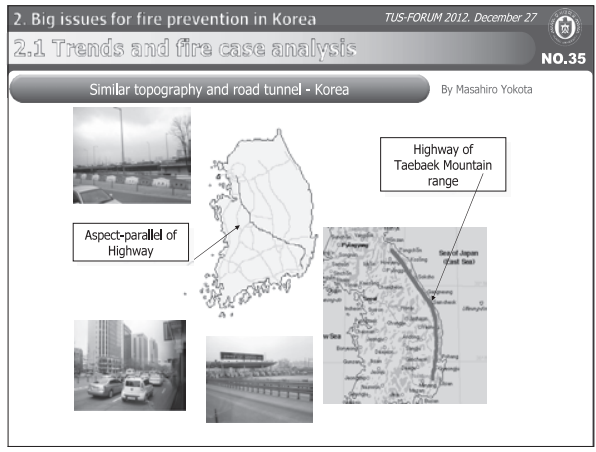

Figure 3-6-35 and also the University of Kanazawa in Japan actually three of us are holding and organizing the joint seminars each year. (Figure 3-6-37)

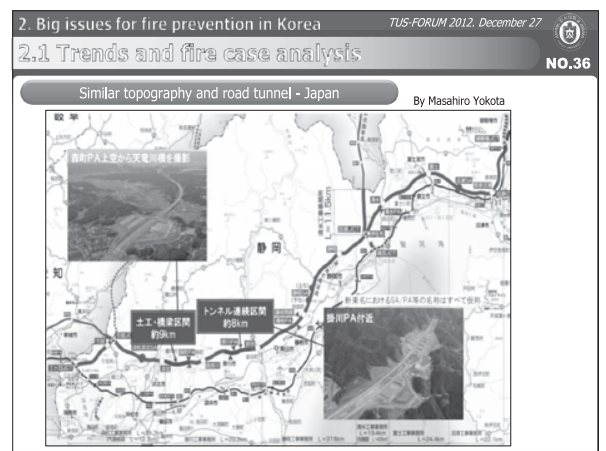

Figure 3-6-36

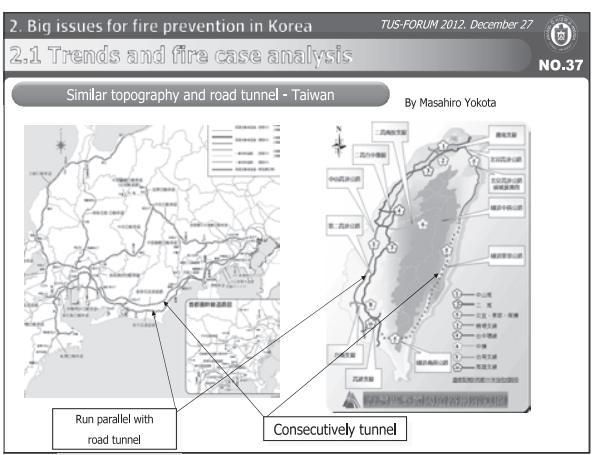

Figure 3-6-37

So mostly the fire in this case is occurring in urban area in a shantytown fire, (Figure 3-6-38) but for the fire prevention district there is - it's set out by the land planning and utilization law and there is a fire protection area. (Figure 3-6-39) It's covered by fire safety law. However, we have not got any concrete measures from these laws. So specific fire control measures can be needed.

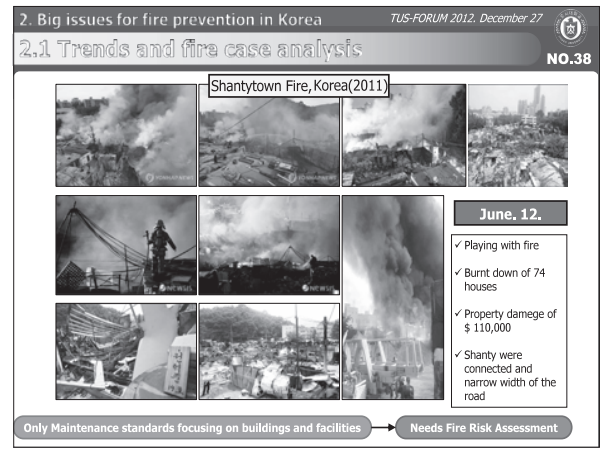

Figure 3-6-38

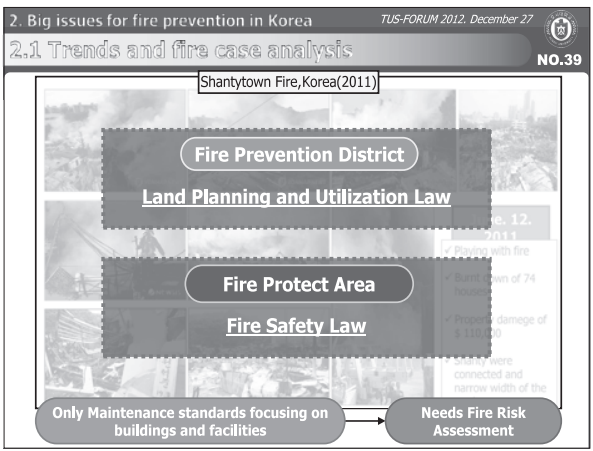

Figure 3-6-39 
Also in Japan there is a building inserts. (Figure 3-6-40) In Japan we have multipurpose buildings including the pubs and the bars. There in the canons and building standards law and fire services law.

There are multiple laws, it's very difficult to control and a special law was set up to cover for these multipurpose facilities. There should be fire risk assessment before they can start use those multipurpose buildings. (Figure 3-6-41)

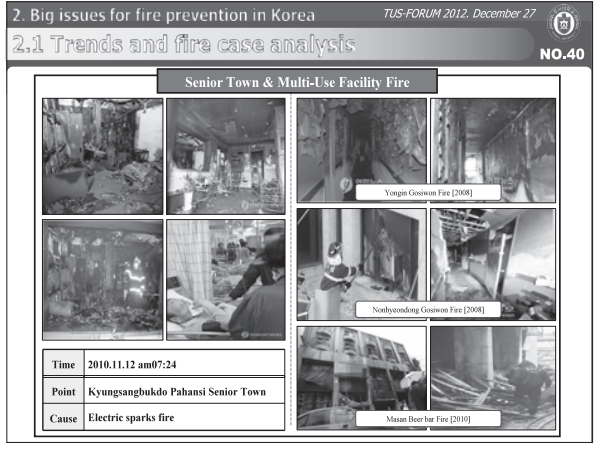

Figure 3-6-40

For these hazardous areas there are many construction laws and fire related laws and special act amended because of the past history incidents. (Figure 3-6-42) This is the summary of the relationship between the events and the law amendments. Our university and the curriculum, I would like to explain about these things.

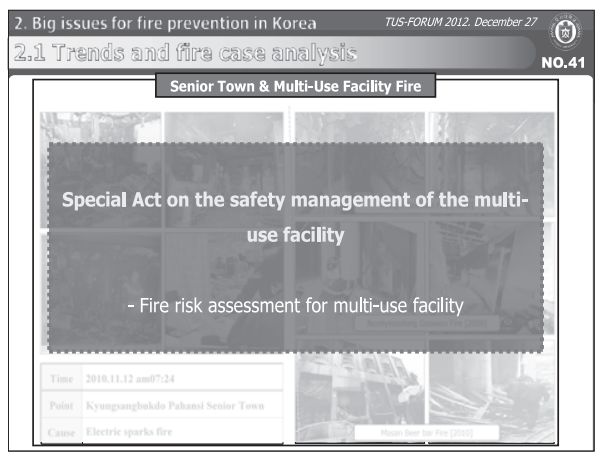

Figure 3-6-41

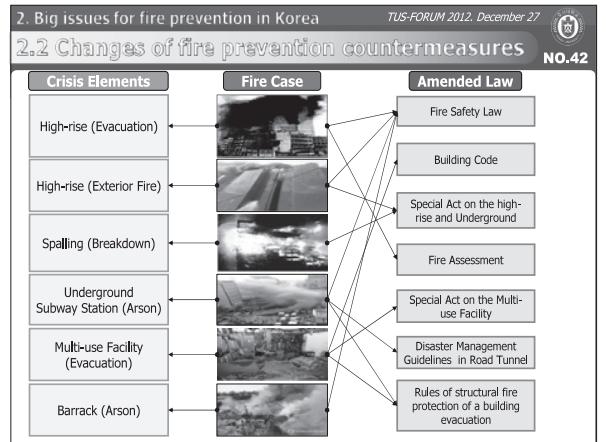

Figure 3-6-42

Our university was established in 1981. (Figure 3-6-43) It's still very young university. But regarding the fire safety in 1995, we created the first course for the 4-year college in Korea. The Fire and Disaster Prevention Department was first established in our university in Korea and we have the MoU with Maryland University in 2003 and also we have signed an MoU with Tokyo University of Science in 2010. (Figure 3-6-44)

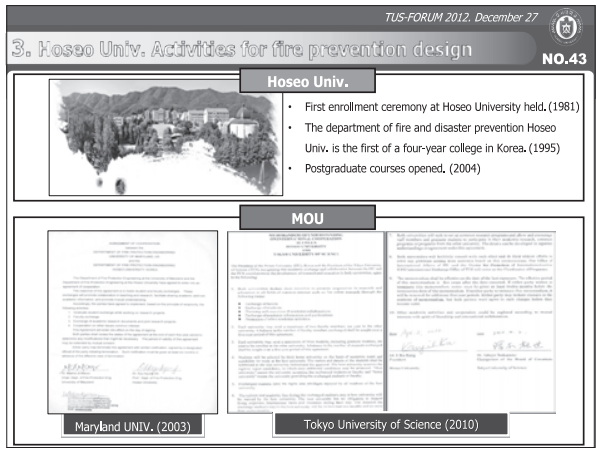

Figure 3-6-43

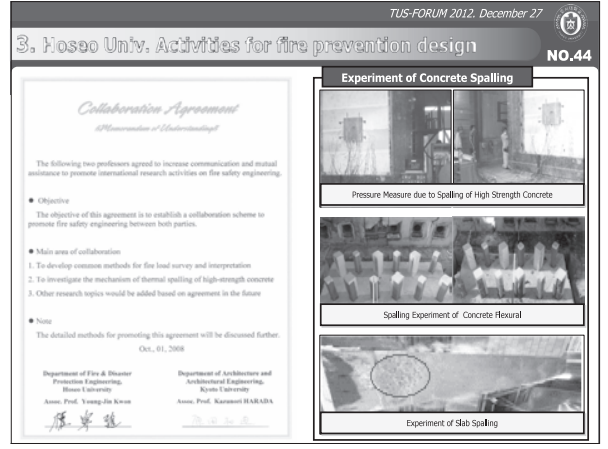

Figure 3-6-44 
Also the joint visit is carried out with Professor Harada of the Kyoto University. We tried to explore the mechanism of the probabilities of the incidents. This is one of the project we are doing. (Figure 3-6-45) To maintain the facility, ISO/TC71 is related to the maintenance and last year the Hong Kong Technical University is the venue of the meeting. (Figure 3-6-46) We proposed that idea and this year at Costa Rica we read a paper and waiting for the voting at this moment. Once the process completes, we can have two cases, one is before the fire and after the fire. How to investigate the damage to building after the fire and how to recover the damage to building, regarding these things we would like to standardize the process.

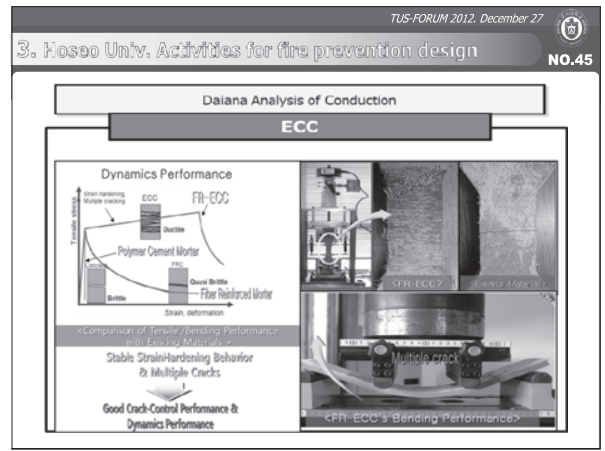

Figure 3-6-45

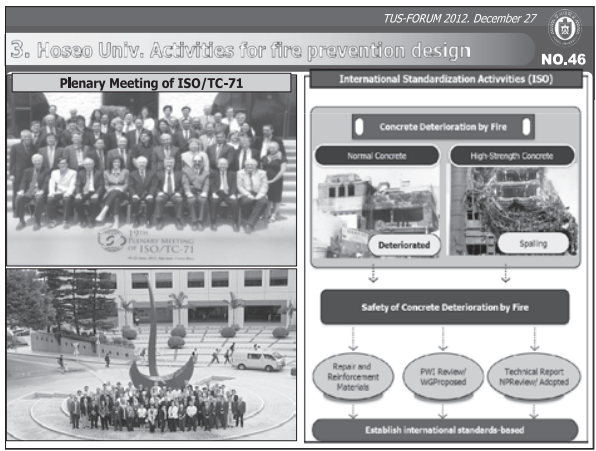

Figure 3-6-46

The wind and fire. (Figure 3-6-47) In this area with Mr. Fan and Mr. Hayashi and Hong Huang and Mr. Ohmiya and from Indonesia and United States, with many specialists we have the study meeting together with them. Next year it would be the fourth meeting and the next year we will have a meeting in Indonesia. This is the Professor Fan's idea to have the international seminar and at that time I was invited and read a paper there.

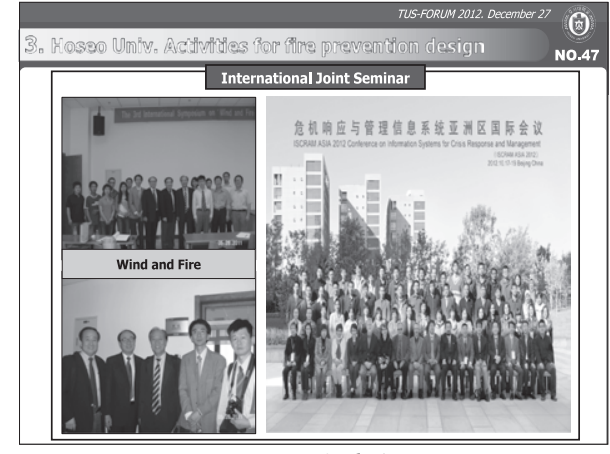

Figure 3-6-47

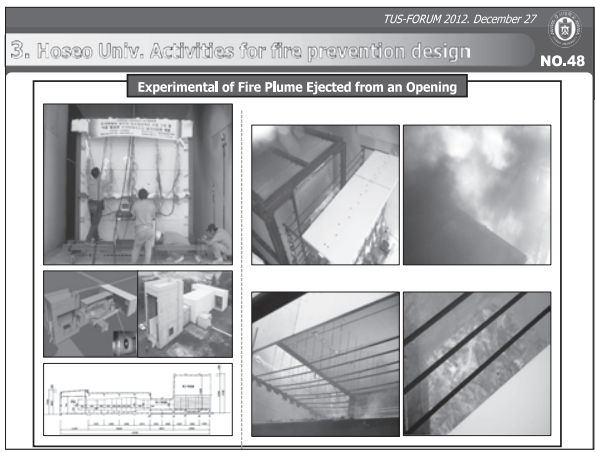

Figure 3-6-48

\section{)}

An international joint project for the urban disaster is also carried out. (Figure 3-6-48) At that time our university and BRI, NIST, Ulster, Professor Choi and with many partners we carried out a project for a year. (Figure 3-6-49) We would like to accelerate these kind of activities more. There was another presenter from Taiwan and the fifth one was carried out in Taiwan, but next one is at Tokyo and third one is Taiwan and the 
fourth one will be carried out in November, fifth in South Korea. Next year it will be carried out in Tokyo. (Figure 3-6-50) Recently in South Korea the fire investigation is carried out scientifically, so we have to do that with the government. In Japan, they follow the term model and in the United States there is a NAPI organization and CFD has also established the organization. So we have the partnership with them and we carry out the investigation.

This is a very basic thing at the investigation of the flammable materials and also in toxicity investigation. (Figure 3-6-51)

Flashover is also another area and the experiment on the exterior fire, the material analysis and as for the tunnel fire (Figure 3-6-52), the vehicle fire is a featured and aged car used and also type of the vehicle, other factors to consider.

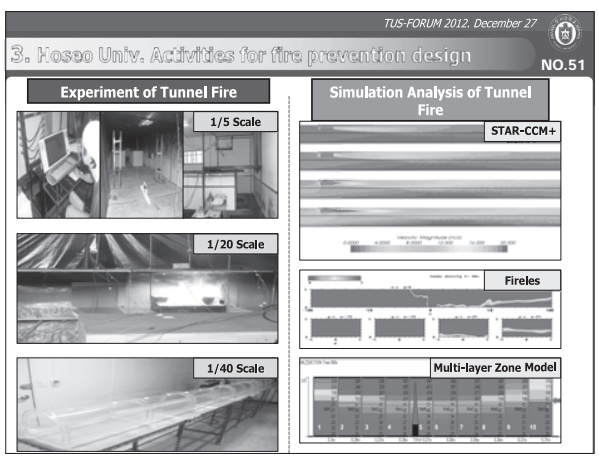

Figure 3-6-51

Investigation of the flammable items, we investigate combustibles with many uses with the cooperation of Professor Ohmiya and also the working speed of the aged people and crowds working speed and these are related to the models of the evacuation. (Figure 3-6-53, 3-6-54, 3-6-55, 3-6-56, 3-6-57)

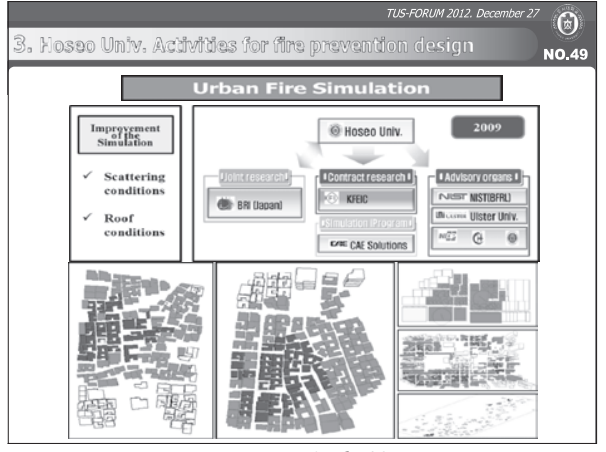

Figure 3-6-49

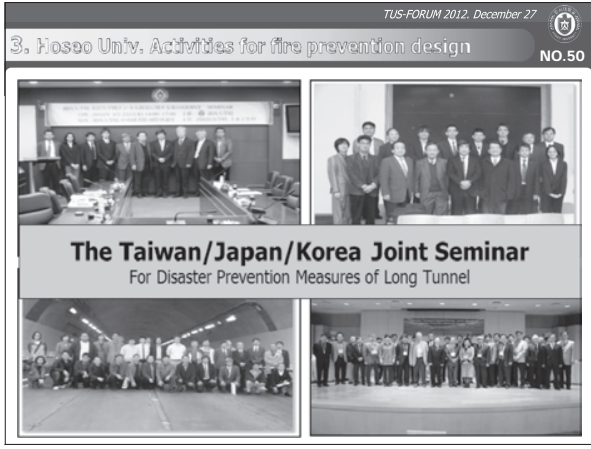

Figure 3-6-50

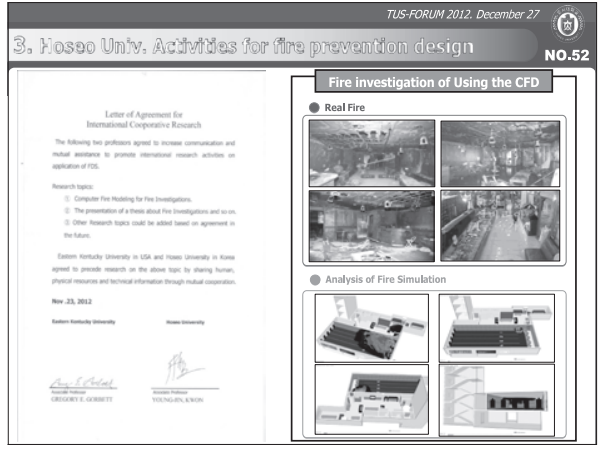

Figure 3-6-52

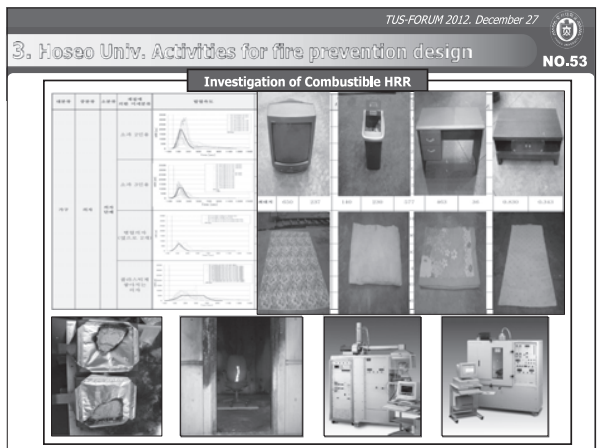

Figure 3-6-53 


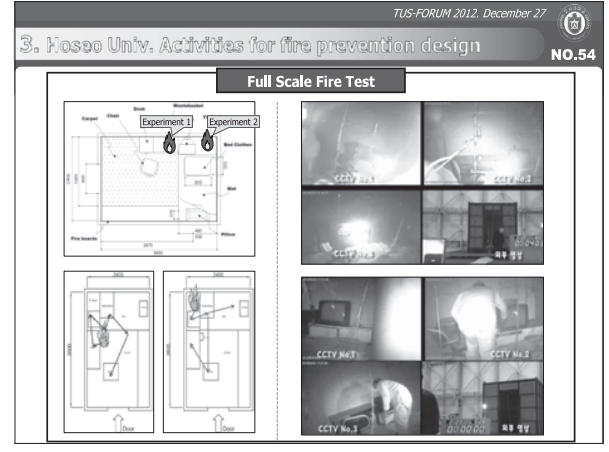

Figure 3-6-54

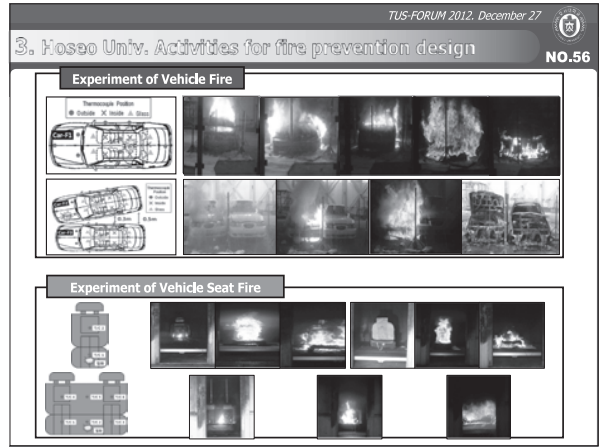

Figure 3-6-56

Lastly we have the department, our department has four areas. (Figure 3-6-58) This is the electric side and mechanical base and chemistry base and architectural base. I am in charge of this architectural base. So other than that architecture there are chemical, electrical, and mechanical, so there are four disciplined professors.

At first we just modeled after the other university's curriculum and then we have established this kind of curriculum. (Figure 3-6-59) In Japan, Japanese society, Professor Tanaka worked, Kasai safety engineering entry textbook and we use it as a main textbook when we teach the students.

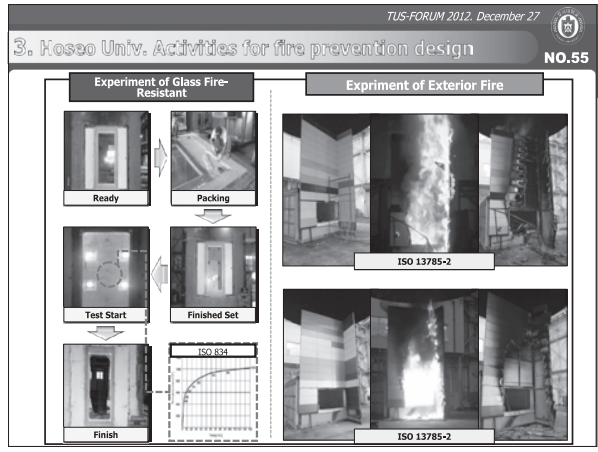

Figure 3-6-55

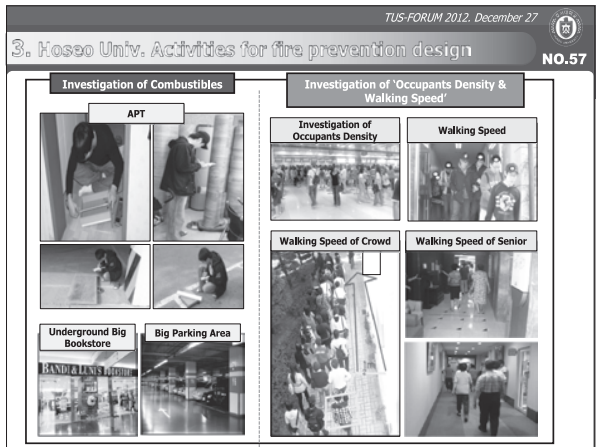

Figure 3-6-57

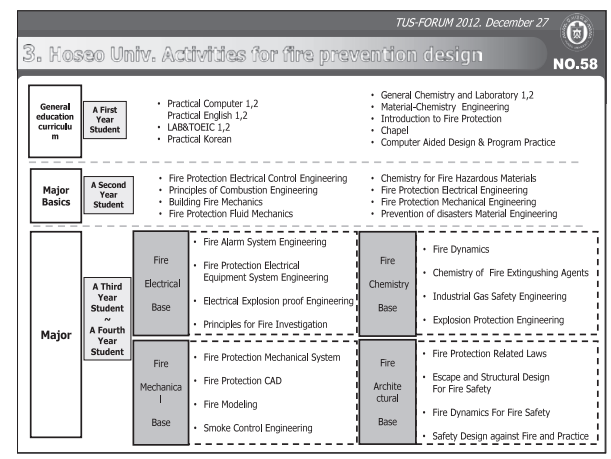

Figure 3-6-58

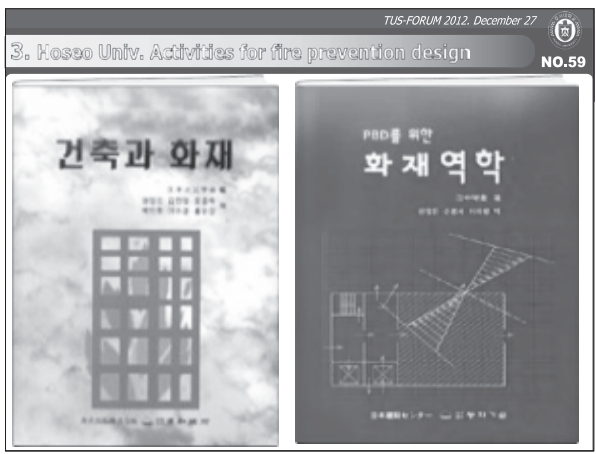

Figure 3-6-59 
As the time has come I have to summarize briefly. (Figure 3-6-60) In Korea there are five weak points, it's just my opinion. First of all is the high-rise buildings and also the underground space development and the increment of aged buildings and aged and disabled people's facilities increase and arson.

These are the five problems and I think we have to focus on these areas. There is our new laws in South Korea and also the education I also introduced. Thank you very much. (Figure 3-6-61)

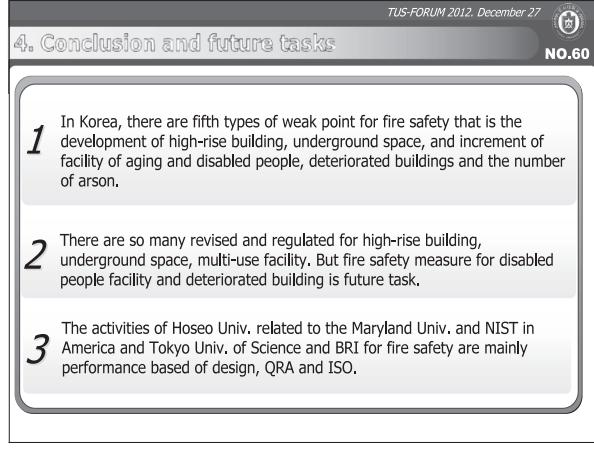

Figure 3-6-60

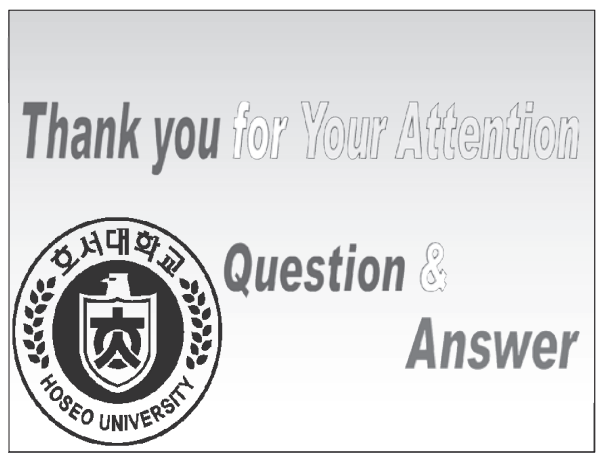

Figure 3-6-61 